\title{
Predicted distribution and habitat loss for the Endangered black-faced black spider monkey Ateles chamek in the Amazon
}

\author{
Rafael M. Rabelo, Jonas R. Gonçalves, Felipe E. Silva, Daniel G. Rocha \\ Gustavo R. Canale, Christine S.S. Bernardo and Jean P. Boubli
}

\begin{abstract}
The rate of deforestation in the Amazon is increasing. Predictive models estimate that as a result of agricultural expansion $40 \%$ of these forests will be lost by 2050 . As a consequence the habitat of forest-dwelling species such as the Endangered black-faced black spider monkey Ateles chamek is being lost, particularly along the arc of deforestation in the Brazilian Amazon. We used species distribution modelling to (1) define the distribution of this spider monkey, using environmental predictors, (2) calculate the area of this distribution covered by the protected area network, and (3) calculate the expected loss of the species' habitat under future scenarios of deforestation. We found that the species occupies only c. $28 \%$ of its extent of occurrence. Only $32 \%$ of the species' area of occupancy is legally protected, and the modelling suggests that $31-40 \%$ of the species' habitat will be lost by 2050 . We highlight three unprotected regions with extensive forest cover that are predicted to become severely deforested by 2050 as priority regions for expanding the protected area network. We also propose landscape management and restoration in three human-modified regions. Our study provides an example of how species distribution modelling can be applied to assess threats to species and support decision makers in implementing conservation actions.
\end{abstract}

RAFAel M. RABELO* (Corresponding author) and Jonas R. GonÇALVES ${ }^{*}$ Centro de Estudos Integrados da Biodiversidade Amazônica, Instituto Nacional de Pesquisas da Amazônia, Manaus, Amazonas, Brazil

E-mail rmrabelo@gmail.com

Felipe E. Silva $\ddagger$ and Daniel G. Rocha $\$$ Coordenação de Pesquisa, Instituto de Desenvolvimento Sustentável Mamirauá, Tefé, Amazonas, Brazil

Gustavo R. Canale Instituto de Ciências Naturais, Humanas e Sociais, Universidade Federal de Mato Grosso, Sinop, Mato Grosso, Brazil

Christine S.S. Bernardo Programa de Pós-Graduação em Ciências Ambientais, Universidade do Estado de Mato Grosso, Cáceres, Mato Grosso, Brazil

JeAn P. Boubli School of Environment \& Life Sciences, University of Salford, Salford, UK

*Also at: Coordenação de Pesquisa, Instituto de Desenvolvimento Sustentável Mamirauá, Tefé, Amazonas, Brazil

$\dagger$ Also at: Programa de Pós-Graduação em Ecologia, Instituto Nacional de Pesquisas da Amazônia, Manaus, Amazonas, Brazil

\$Also at: School of Environment \& Life Sciences, University of Salford, Salford, UK

\$Also at: Graduate Group in Ecology, Department of Wildlife, Fish, and Conservation Biology, University of California Davis, Davis, California, USA

Received 14 November 2017. Revision requested 17 January 2018.

Accepted 12 April 2018. First published online 18 December 2018.
Keywords Amazon, Ateles chamek, Brazil, deforestation, Maxent, primate, protected area, reserve design

Supplementary material for this article is available at https://doi.org/10.1017/So030605318000522

\section{Introduction}

Cince the late 1960s Amazonian forests have been exposed $\checkmark$ to unprecedented levels of disturbance, mainly as a result of the intensification of extensive mono-crop agriculture, cattle ranching, logging and the ecological footprints of urban areas (Davidson et al., 2012). Predictive models of deforestation estimate that $40 \%$ of these forests will be lost by 2050 , and c. $25 \%$ of mammal species may lose $>40 \%$ of their habitat in the Amazon (Soares-Filho et al., 2006).

Habitat loss and fragmentation are considered to be the main direct threat to primates (Estrada et al., 2017). Neotropical primates, which spend all their lives in trees, rarely descending to the forest floor or crossing open areas, often occupy important trophic positions in forest food webs (Terborgh, 1983). They have an important role as seed dispersers (Hawes \& Peres, 2014) and their demise would cause cascading ecological effects. The black-faced black spider monkey Ateles chamek is an Amazonian primate species categorized as Endangered on the IUCN Red List (Wallace et al., 2008). The forests in the southern portion of its range are among the areas worst affected by deforestation as a result of the expanding Brazilian agricultural frontier, a region referred to as the arc of deforestation.

Species distribution data are required to indicate priority regions for establishing conservation actions (Brooks et al., 2006), and species distribution models are valuable tools for species and habitat conservation plans, reserve design, and habitat management and restoration (Franklin, 2009). These models evaluate the relationships between occurrences of a species and a set of spatially explicit environmental variables, to estimate the species' environmental requirements and project them in geographical space. Such models have been widely applied for supporting decision-making to inform conservation actions (Villero et al., 2017).

Here we use species distribution modelling to predict the distribution of the black-faced black spider monkey. Our objectives are to quantify the areas with highest habitat 
suitability that fall within protected areas and Indigenous lands, and to estimate current and future habitat loss for the species, using two scenarios of deforestation across the Amazon Basin (Soares-Filho et al., 2006). We propose priority areas for the conservation of this species, new protected areas and the restoration of connectivity in the forest landscape.

\section{Methods}

\section{Species distribution modelling}

We used the maximum entropy algorithm, in MAXENT 3.3.3, to map habitat suitability for the species and estimate its potential distribution (Phillips \& Dudík, 2008). This algorithm seeks non-random relationships between species' occurrences and environmental variables, building a model that estimates the species' potential distribution according to relevant variables.

We gathered data on species occurrence from the literature, online datasets and personal observations spanning 1979-2017 (Supplementary Table 1). We inspected all records, excluding those with uncertain species identification, inaccurate geographical location, or from areas already deforested, and retaining pre 1990 records only if they were from areas that still have pristine forests, assuming that the species is still likely to be present. After excluding such records, we randomly removed duplicate records within a $30 \mathrm{~km}$ radius to control for sampling bias (Boria et al., 2014), as records of species in the Amazon are commonly spatially clustered in sites that have been well studied. We obtained a total of 172 occurrence records of A. chamek, of which, after filtering, 99 were used in the model (Supplementary Fig. 1). We then plotted all records in a geographical information system (QGIS 2.14; QGIS Development Team, 2015) and created a polygon layer that included all records. As the ranges of Amazonian primates are usually limited by large rivers (e.g. Boubli et al., 2015), we drew the boundaries of this polygon following rivers, encompassing the entire interfluvial region that included species records (Fig. 1). This polygon was defined as the species' extent of occurrence (sensu IUCN, 2012), and it was used to parameterize the model and to project the species' distribution.

We chose 19 available environmental variables that we would expect to influence the species' distribution (Supplementary Table 2). These variables consisted of climatic (10), topographic (4), edaphic (2) and vegetation (3) layers at $10 \mathrm{~km}$ resolution. We used the species' extent of occurrence polygon to crop the environmental variables and then performed a pair-wise correlation test (Supplementary Table 3). We removed all highly correlated variables $(r>|0.8|)$ to avoid collinearity (Carvalho et al., 2017). We used nine predictor variables in the model: temperature seasonality; minimum temperature of coldest month; annual precipitation; precipitation seasonality; annual potential evapotranspiration; flooded areas; compound topographic index, which is a measure of soil wetness; height above nearest drainage; and net primary productivity.

We used 5,000 random background records and divided the occurrences into 10 subsets (one for training, nine for testing), using the cross-validation technique to validate the model (Phillips \& Dudík, 2008; see Supplementary Material 1 for further details of the modelling procedure). We converted the continuous prediction of habitat suitability into a binary prediction by setting a threshold of habitat suitability, above which we considered that habitat was occupied (i.e. the species' area of occupancy, sensu IUCN, 2012). We accomplished this by choosing the threshold with equal sensitivity (rate of true presences) and specificity (rate of true absences). We evaluated model accuracy with the True Skill Statistic (TSS), an effective and well-accepted measure of accuracy for binary predictions (Allouche et al., 2006). All procedures were performed in $R$ v.3.3.3 ( $\mathrm{R}$ Development Core Team, 2015).

\section{Threat assessment and priority regions for conservation}

We used QGIS to overlay the prediction of species distribution, the protected areas and Indigenous lands (UNEP-WCMC, 2016), and the current and future scenarios of forest cover modelled by Soares-Filho et al. (2006). These authors modelled the future patterns of deforestation across the Amazon Basin (2002-2050) for two scenarios: (1) a business-as-usual scenario, which considers that current deforestation trends will continue, highways scheduled for paving will be paved, compliance with legislation requiring forest reserves on private land will remain low, and new protected areas will not be implemented; and (2) a governance scenario, which also considers the current deforestation trends but assumes a $50 \%$ limit imposed for deforested land within each basin's sub-region, and that existing and proposed protected areas play a determinant role in hindering deforestation. We calculated the extent of areas currently covered by protected areas and Indigenous lands, as well as current and future forested, deforested and non-forest areas within the species' area of occupancy.

We used these overlaid layers to indicate priority regions for the conservation of the species. We indicate regions for expanding the protected area network as those (1) with $>40 \%$ habitat suitability for the species; (2) with forest cover $>75 \%$; (3) expected to lose $>50 \%$ of forested area by 2050 because they are not under any protection; and (4) that are adjacent to existing protected areas/Indigenous lands. We also indicated human-modified regions (1) with $>40 \%$ of habitat suitable for the species, (2) that have already been deforested but are predicted to lose $>70 \%$ of forest area by 2050 , and (3) that are adjacent to existing 


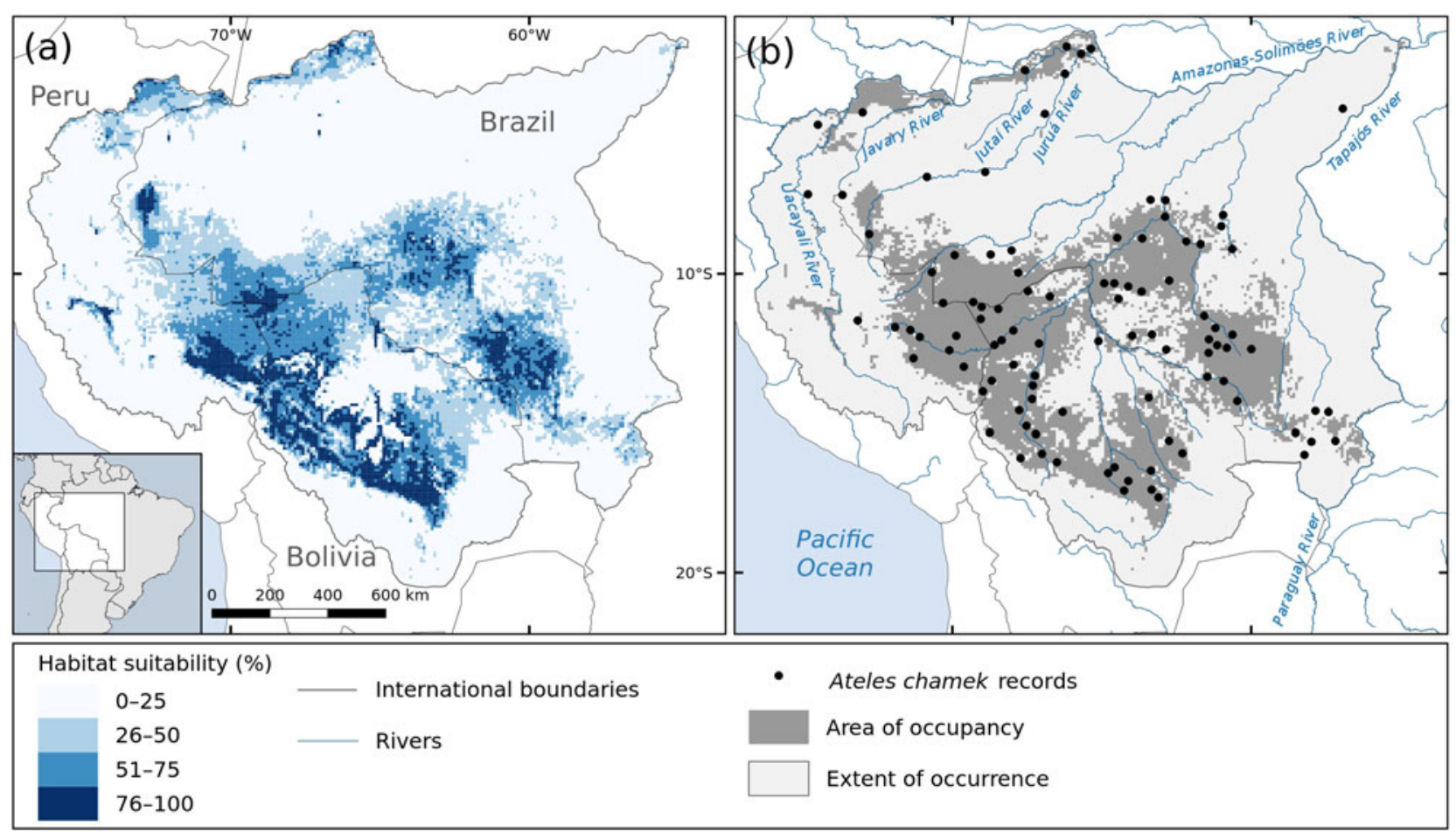

FIG. 1 (a) Habitat suitability and (b) predicted area of occupancy (i.e. areas with habitat suitability $>35.75 \%$ ) for the black-faced black spider monkey Ateles chamek in the Amazon and Upper-Paraguay Basins; the area of occupancy comprises $28 \%$ of the species' extent of occurrence.

protected areas/Indigenous lands, as potential areas for landscape planning, management and/or restoration.

\section{Results}

The habitat suitability and predicted species distribution are shown in Fig. 1. According to our model, the species has a considerably reduced area of occupancy within its extent of occurrence, being expected to occupy an area of $927,754 \mathrm{~km}^{2}$ (only $28 \%$ of the extent of occurrence). We found that the species is more likely to occur in the central-southern region of its range, where the habitat suitability is higher (Fig. 1). We also found suitable habitats for the species in the north-west of its range, in the Amazonas-Javary interfluviual region, in Peru, and along the Lower-Jutaí and Juruá rivers, in Brazil.

The most important variables in the model were temperature seasonality, net primary productivity and potential evapotranspiration, which jointly contributed $57 \%$ to the model gain in all iterations $(24,21$ and $12 \%$, respectively; Supplementary Table 4). According to our model, higher forest productivity and higher temperature variation are associated with higher habitat suitability for the species. The higher the potential evapotranspiration (i.e. drier environments), the lower the habitat suitability for the species (Supplementary Fig. 2). The mean threshold of equal sensitivity-specificity was $35.75 \%$, above which we consider that the species is present. The model-averaged TSS score was $0.56 \pm \mathrm{SD} 0.05$, and therefore we are confident of the accuracy of our prediction (Supplementary Material 1).

We found that only $297,603 \mathrm{~km}^{2}$ (32\% of the species' area of occupancy) lies within protected areas $\left(231,009 \mathrm{~km}^{2} ; 24 \%\right)$ and Indigenous lands $\left(81,489 \mathrm{~km}^{2} ; 8 \%\right)$. Based on the deforestation estimates (Soares-Filho et al., 2006), by 2002 the species had already lost $15 \%$ (c. $127,306 \mathrm{~km}^{2}$ ) of the forest cover within its predicted area of occupancy (Fig. 2). Most of the forest loss occurred in Rondônia state, in Brazil. According to the future scenarios of deforestation, the species may lose $31 \%\left(273,287 \mathrm{~km}^{2}\right)$ of its highly suitable habitat in the governance scenario, and up to $40 \%\left(377,951 \mathrm{~km}^{2}\right)$ in the business-as-usual scenario (Fig. 2).

We indicate six priority regions for the conservation of the species (Supplementary Fig. 3; Table 1). Three of these priority regions are proposed for the designation of new protected areas (Supplementary Fig. 3a-c). One of these regions encompasses three countries: Peru, Bolivia and Brazil (Supplementary Fig. 3a), and the other two lie entirely in Brazil (Supplementary Fig. 3b) and Bolivia (Supplementary Fig. 3c). Three other human-modified regions are indicated as areas for landscape planning, involving protection of forest remnants, as well as landscape management (Supplementary Fig. $3 \mathrm{~d}-\mathrm{f}$ ). Two of these are in Rondônia state in Brazil (Supplementary Fig. 3d, e), and one in Santa Cruz department in Bolivia (Supplementary $3 \mathrm{f}$ ). 

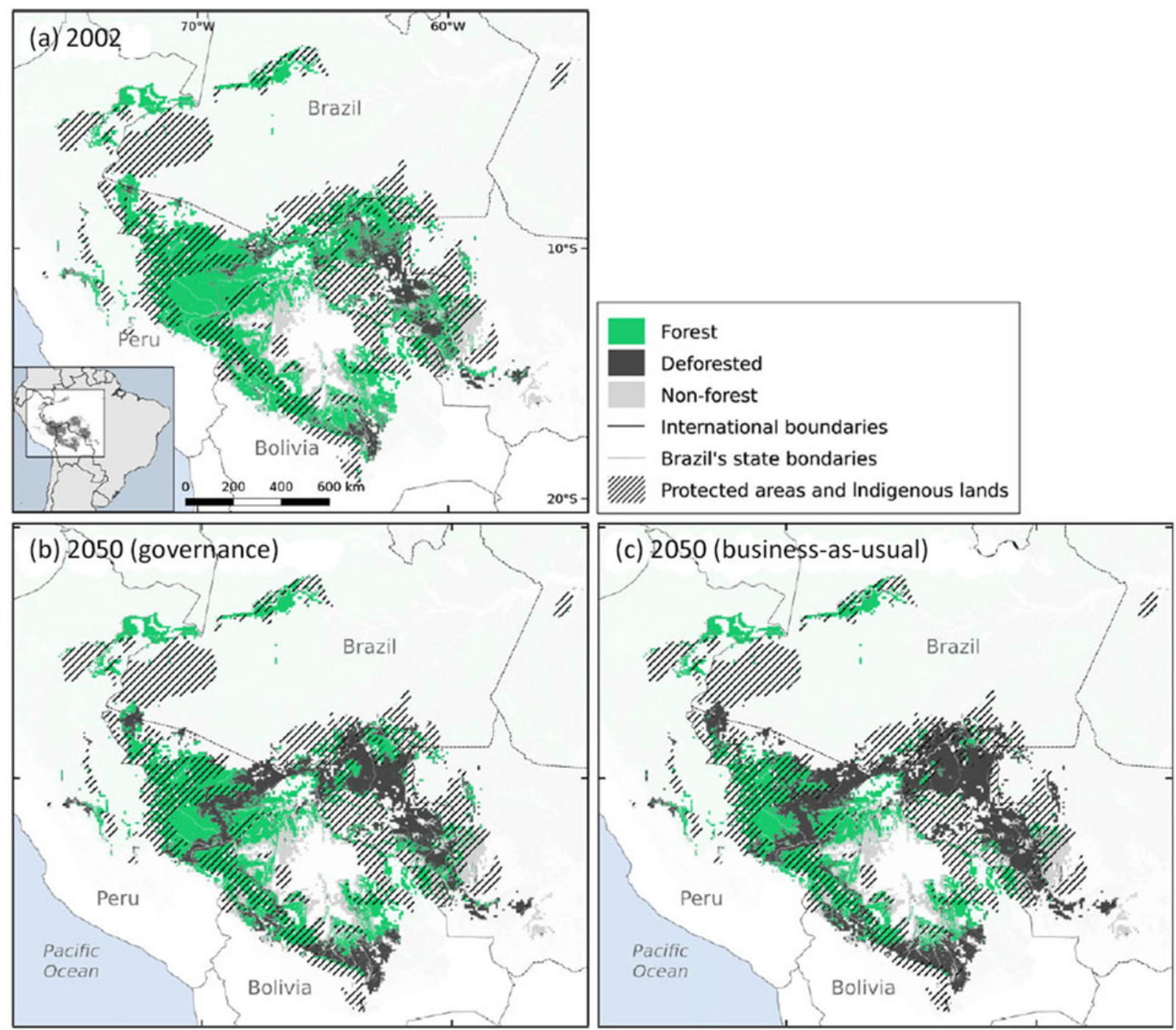

FIG. 2 Habitat loss and protected area network cover within the predicted distribution of A. chamek in Amazonia by 2050, according to the governance (b) and business-as-usual (c) scenarios of deforestation, relative to the situation in 2002 (a). Data on deforestation scenarios are from Soares-Filho et al. (2006).

\section{Discussion}

We have compiled the largest published dataset of $A$. chamek occurrence records to date, and found that the species occurs beyond the extent proposed by IUCN (Wallace et al., 2008; Supplementary Fig. 1), as recorded by Palminteri et al. (2011), Rabelo et al. (2014) and Santos-Filho et al. (2017). However, according to our model, the species occupies only c. $28 \%$ of its extent of occurrence; this is empirically based information that should be taken into account for a species of conservation concern.

Following the definitions of Soberón \& Nakamura (2009), which have been adopted for the IUCN criteria (IUCN, 2012), a species' extent of occurrence is the area that is/has been accessible to the species, given its dispersal ability, during a given time frame. However, it is not expected that a species occupies its entire extent of occurrence uniformly, because of biotic or environmental limitations. In this context, having set the threshold of habitat suitability above which we expect the species to be present, we may assume that (1) the areas within the extent of occurrence with habitat suitability $>35.75 \%$ correspond to the species' area of occupancy (Fig. 1b); (2) species records located within the area of occupancy correspond to populations occurring in highly suitable habitats; and (3) records located outside the area of occupancy represent populations occurring in habitat with environmental constraints.

It could be argued that our model did not predict suitable areas for the species in the central-north and east of the species' extent of occurrence because of the absence of records in these regions. However, there have been exhaustive and long-term primate surveys in those regions that did not 
TABLE 1 Forest cover in the priority regions for the conservation of the black-faced black spider monkey Ateles chamek, based on two future scenarios of deforestation (governance, governance; business-as-usual) in the Amazon Basin (Soares-Filho et al., 2006).

\begin{tabular}{|c|c|c|c|c|c|}
\hline Conservation action & Region & Land cover & $\begin{array}{l}2002 \text { area, } \mathrm{km}^{2} \\
(\%)\end{array}$ & $\begin{array}{l}2050 \text { (governance) area, } \\
\mathrm{km}^{2}(\%)\end{array}$ & $\begin{array}{l}2050 \text { (business as usual) } \\
\text { area, } \mathrm{km}^{2}(\%)\end{array}$ \\
\hline \multirow{9}{*}{$\begin{array}{l}\text { Expansion of protected } \\
\text { area network }\end{array}$} & \multirow[t]{3}{*}{ Cruzeiro } & Forested & $15,618.96(88.0)$ & $8,639.23(49.5)$ & $1,882.73(10.8)$ \\
\hline & & Deforested & $1,841.24(10.4)$ & $8,522.67(48.8)$ & $15,279.16(87.5)$ \\
\hline & & Non-forested & $296.34(1.7)$ & $296.34(1.7)$ & $296.34(1.7)$ \\
\hline & \multirow[t]{3}{*}{ Assis Brasil } & Forested & $60,835.13(91.7)$ & $35,579.27(53.6)$ & $26,040.17(39.3)$ \\
\hline & & Deforested & $4,940.93(7.4)$ & $30,196.79(45.5)$ & $39,735.90(59.9)$ \\
\hline & & Non-forested & $547.24(0.8)$ & $547.24(0.8)$ & $547.24(0.8)$ \\
\hline & \multirow[t]{3}{*}{$\mathrm{La} \mathrm{Paz}$} & Forested & $16,694.67(74.3)$ & $7,849.98(34.9)$ & $4,223.80(18.8)$ \\
\hline & & Deforested & $1,590.34(7.1)$ & $10,435.03(46.4)$ & $14,061.22(62.6)$ \\
\hline & & Non-forested & $4,186.26(18.6)$ & $4,186.26(18.6)$ & $4,186.26(18.6)$ \\
\hline \multirow[t]{9}{*}{ Landscape management } & \multirow[t]{3}{*}{ Porto Velho } & Forested & $18,251.43(47.3)$ & $3,406.89(8.8)$ & $387.21(1.0)$ \\
\hline & & Deforested & $20,105.51(52.1)$ & $34,950.05(90.6)$ & $38,187.04(98.5)$ \\
\hline & & Non-forested & $209.41(0.5)$ & $209.41(0.5)$ & $209.41(0.5)$ \\
\hline & \multirow[t]{3}{*}{ Vilhena } & Forested & $9,545.03(36.4)$ & $3,965.00(15.0)$ & $573.91(2.2)$ \\
\hline & & Deforested & $13,633.50(51.9)$ & $19,318.24(73.2)$ & $22,630.31(86.0)$ \\
\hline & & Non-forested & 3,076.97 (11.7) & $3,108.58(11.8)$ & $3,108.58(11.8)$ \\
\hline & \multirow[t]{3}{*}{ Santa Cruz } & Forested & $32,108.17(53.8)$ & $13,600.90(22.8)$ & $8,030.75(13.4)$ \\
\hline & & Deforested & $18,990.30(31.8)$ & $37,497.56(62.8)$ & $43,067.72(72.1)$ \\
\hline & & Non-forested & $8,622.43(14.4)$ & $8,622.43(14.4)$ & $8,622.43(14.4)$ \\
\hline
\end{tabular}

record the species, or recorded it at very low densities (Peres, 1997; Haugaasen \& Peres, 2005; Kasecker, 2006; Bastos, 2012; J.R. Gonçalves et al., unpubl. data). Therefore, we do not believe that our model was biased by the absence of records in these regions. We believe that these regions were predicted to be unoccupied because of unsuitable (or less suitable) environmental conditions.

According to our model, temperature variation and net primary productivity were the most important variables for predicting the species' distribution (Supplementary Table 4). Trees in seasonal and highly diverse forests tends to produce fruits asynchronously (van Schaik et al., 1993), and forests with high primary productivity generally have high fruit production (Clark et al., 2001). Spider monkeys are primary consumers and have been consistently identified to be among the most frugivorous Neotropical primates (Di Fiore et al., 2008). Thus, we would expect that areas with higher temperature seasonality and primary productivity would have high habitat suitability for the species.

We found that $68 \%$ of the species' area of occupancy is outside protected areas. As habitat loss advances in tropical forests, protected areas become essential refuges for wildlife. Protected areas harbour higher species richness and abundance than unprotected areas, emphasizing their importance for conservation of viable populations in natural ecosystems (Gray et al., 2016). As studies have consistently shown the role of protected areas and Indigenous lands in safeguarding Amazonian forests (Nepstad et al., 2006; Dobrovolski et al., 2011; Blackman et al., 2017), we believe that they are still an effective tool for the conservation of spider monkeys and many other species.
Although expanding the protected area network would help to inhibit habitat loss, this may not be sufficient for the conservation of the black-faced black spider monkey. Even under the most conservative scenario of deforestation (the governance scenario), the deforested area within the species' distribution in 2050 is expected to be twice as large as it was in 2002. The governance scenario assumes effective implementation of environmental legislation across the Amazon Basin through the enforcement of mandatory forest reserves on private properties, agro-ecological zoning of land use and the expansion of the protected area network (Nepstad et al., 2002), requiring international and national conservation efforts. However, it is unlikely that frontier governance will be refined in the way required, especially following the controversial changes in Brazilian legislation regulating land use on private properties (Soares-Filho et al., 2014). Therefore, the business-as-usual scenario is more realistic: it will result in a loss of $40 \%$ of the forested area within the range of the black-faced black spider monkey.

We identify six priority regions for the conservation of the black-faced black spider monkey, all of them currently outside protected areas. Three of these priority regions still have a considerable amount of forest cover (Supplementary Fig. 3; Table 1) but according to the deforestation scenarios these areas will become severely deforested because they are not under protection. Spider monkeys are known for their long daily journeys (460-5,690 $\mathrm{m}$ ) and large home ranges (153-340 ha), which overlap little with the home ranges of other groups, and often show a preference for using tall forest types and may avoid edge habitats (Wallace, 2008). 
Additionally, they are particularly vulnerable to habitat loss and fragmentation, which means that large areas of continuous forest (or at least large forest patches) are more likely to sustain viable populations of the species (Ramos-Fernández \& Wallace, 2008). Therefore, we suggest these three regions as priority areas for implementation of new protected areas to conserve these large forest tracts.

We also propose three priority regions where conservation measures for regulating land use and management of private lands would help to protect forest remnants and conserve the species outside reserves. Given the scale of our analysis (10 km resolution), we are targeting wide-scale human-modified regions, where infrastructure development and large-scale farming have caused severe habitat loss and fragmentation. Forest-dwelling species, such as spider monkeys, may potentially persist in human-modified regions if forest connectivity is managed at the landscape scale (Pardini et al., 2010), particularly in this case as we found high habitat suitability for the species in these regions. The restoration of forest connectivity could be planned by the implementation of environmental legislation that regulates vegetation loss and restoration within private properties, especially in riparian zones. However, further fine-scale studies must be conducted to consolidate landscape management within these regions.

This study provides key information for the conservation of the threatened black-faced black spider monkey, as required by IUCN and the Brazilian National Action Plans: an update of the species' extent of occurrence, the predicted area of occupancy of the species, the protection status of suitable areas for the species, and a recommendation of priority regions for establishing protected areas and for enhancing habitat connectivity (e.g. Jerusalinksy et al., 2011). The black-faced black spider monkey is only one of thousands of species that are being threatened by land-cover changes in the arc of deforestation in the Amazon. This species could be endorsed by conservation organizations as a flagship species to motivate public support for conservation actions (e.g. Home et al., 2009). Our findings will be of value in assessing the conservation status of the species, and establishing goals in National Action Plans for the conservation of the species. We are passing our recommendations to relevant stakeholders to facilitate this process.

Acknowledgements This paper was written during a visiting internship by RMR to the University of Salford, funded by the Student Conference on Conservation Science Miriam Rothschild Travel Bursary Programme. RMR received research fellowships from the Brazilian National Research Council (CNPq, 313108/2016-1, 142352/ 2017-9). DGR received a scholarship from CAPES/Doutorado Pleno no Exterior (88881.128140). We thank Parque Nacional dos Campos Amazônicos and Parque Nacional Mapinguari for logistical support in obtaining new species records, and Cazuza Junior, Fernando Figueiredo and Marcelo Santos Jr for their contribution of ideas for this research.
Author contributions Study design, data collection, analysis and writing: RMR; data collection, interpretation of results, and assistance with writing: JRG, FES and DGR; study design, interpretation of results, and assistance with writing: GRC, CSSB and JPB.

\section{Conflicts of interest None.}

Ethical standards This research complied with the Oryx Code of Conduct.

\section{References}

Allouche, O., Tsoar, A. \& Kadmon, R. (2006) Assessing the accuracy of species distribution models: prevalence, kappa and the true skill statistic (TSS). Journal of Applied Ecology, 43, 1223-1232.

B Astos, A.N. (2012) O efeito da estrutura do habitat na abundância de populações de macaco-barrigudo (Lagothrix cana) no interflúvio purus-madeira, Amazônia Central. MSc thesis. Instituto Nacional de Pesquisas da Amazônia, Manaus, Brazil.

Blackman, A., Corral, L., Lima, E.S. \& Asner, G.P. (2017) Titling Indigenous communities protects forests in the Peruvian Amazon. Proceedings of the National Academy of Sciences of the United States of America, 114, 4123-4128.

Boria, R.A., Olson, L.E., Goodman, S.M. \& Anderson, R.P. (2014) Spatial filtering to reduce sampling bias can improve the performance of ecological niche models. Ecological Modelling 275, 73-77.

Boubli, J.P., Ribas, C., Lynch Alfaro, J.W., Alfaro, M.E., Da Silva, M.N.F., Pinho, G.M. \& Farias, I.P. (2015) Spatial and temporal patterns of diversification on the Amazon: a test of the riverine hypothesis for all diurnal primates of Rio Negro and Rio Branco in Brazil. Molecular Phylogenetics and Evolution, 82, 400-412.

Brooks, T.M., Mittermeier, R.A., Da Fonseca, G.A.B., Gerlach, J., Hoffmann, M., Lamoreux, J.F. et al. (2006) Global biodiversity conservation priorities. Science, 313, 58-61.

Carvalho, D.L., Sousa-Neves, T., Cerqueira, P.V., Gonsioroski, G., Silva, S.M., Silva, D.P. \& SAntos, M.P.D. (2017) Delimiting priority areas for the conservation of endemic and threatened Neotropical birds using a niche-based gap analysis. PLOS ONE, 12, eo171838.

Clark, D.A., Brown, S., Kicklighter, D.W., Chambers, J.Q., Thomlinson, J.R. \& Ni, J. (2001) Measuring net primary production in forests: concepts and field methods. Ecological Applications, 11, 356-370.

Davidson, E.A., de Araújo, A.C., Artaxo, P., Balch, J.K., Foster Brown, I., Bustamante, M.M.C. et al. (2012) The Amazon basin in transition. Nature, 481, 321-328.

Di Fiore, A., Link, A. \& Dew, J.L. (2008) Diets of wild spider monkeys. In Spider Monkeys: Behavior, Ecology and Evolution of the Genus Ateles (ed. C. Campbell), pp. 81-137. Cambridge University Press, Cambridge, UK.

Dobrovolski, R., Diniz-Filho, J.A.F., Loyola, R.D. \& De Marco, JR, P. (2011) Agricultural expansion and the fate of global conservation priorities. Biodiversity and Conservation, 20, 2445-2459.

Estrada, A., Garber, P.A., Rylands, A.B., Roos, C., Fernandez-Duque, E., Di Fiore, A. et al. (2017) Impending extinction crisis of the world's primates: why primates matter. Science Advances, 3, e1600946.

Franklin, J. (2009) Mapping Species Distributions: Spatial Inference and Prediction. Cambridge University Press, New York, USA.

Gray, C.L., Hill, S.L.L., Newbold, T., Hudson, L.N., BÖrger, L., Contu, S. et al. (2016) Local biodiversity is higher inside than outside terrestrial protected areas worldwide. Nature Communications, 7, 12306. 
Haugahen, T. \& Peres, C.A. (2005) Primate assemblage structure in Amazonian flooded and unflooded forests. American Journal of Primatology, 67, 243-258.

Hawes, J.E. \& Peres, C.A. (2014) Ecological correlates of trophic status and frugivory in neotropical primates. Oikos, 123, 365-377.

Home, R., Keller, C., Nagel, P., Bauer, N. \& Hunziker, M. (2009) Selection criteria for flagship species by conservation organizations. Environmental Conservation, 36, 139-148.

IUCN (2012) IUCN Red List Categories and Criteria (version 3.1), 2nd edition. IUCN, Gland, Switzerland and Cambridge, UK.

Jerusalinksy, L., Talebi, M. \& Melo, F. (2011) Plano de Ação Nacional para a Conservação dos Muriquis. ICMBio, Brasília, Brazil.

KASECKER, T.P. (2006) Efeito da estrutura do hábitat sobre a riqueza e composição de comunidades de primatas da RDS Piagaçu-Purus, Amazônia Central, Brasil. MSc thesis. Instituto Nacional de Pesquisas da Amazônia/Universidade Federal do Amazonas, Manaus, Brazil.

Nepstad, D., McGrath, D., Alencar, A., Barros, A.C., Carvalho, G., Santilli, M. \& Vera Diaz, M.C. (2002) Frontier governance in Amazonia. Science, 295, 629-631.

Nepstad, D., Schwartzman, S., Bamberger, B., Santilli, M., Ray, D., SChlesinger, P. et al. (2006) Inhibition of Amazon deforestation and fire by parks and Indigenous lands. Conservation Biology, 20, 65-73.

Palminteri, S., Powell, G.V.N. \& Peres, C.A. (2011) Regional-scale heterogeneity in primate community structure at multiple undisturbed forest sites across south-eastern Peru. Journal of Tropical Ecology, 27, 181-194.

Pardini, R., Bueno, A.A., Gardner, T.A., Prado, P.I. \& Metzger, J. P. (2010) Beyond the fragmentation threshold hypothesis: regime shifts in biodiversity across fragmented landscapes. PLOS ONE, 5, e13666.

Peres, C.A. (1997) Primate community structure at twenty western Amazonian flooded and unflooded forests. Journal of Tropical Ecology, 13, 381-405.

Phillips, S.J. \& Dudí, M. (2008) Modeling of species distributions with Maxent: new extensions and a comprehensive evaluation. Ecography, 31, 161-175.

QGIS Development Team (2015) QGIS Geographical Information System. Open Source Geospatial Foundation Project.

R Development Core Team (2015) R: A Language and Environment for Statistical Computing. R Foundation for Statistical Computing, Vienna, Austria.

Rabelo, R.M., Silva, F.E., Vieira, T., Ferreira-Ferreira, J., Paim, F.P., Dutra, W. et al. (2014) Extension of the geographic range of
Ateles chamek (Primates, Atelidae): evidence of river-barrier crossing by an Amazonian primate. Primates, 55, 167-171.

Ramos-Fernández, G. \& Wallace, R. (2008) Spider monkey conservation in the twenty-first century: recognizing risks and opportunities. In Spider Monkeys: Behavior, Ecology and Evolution of the Genus Ateles, 1st edition (ed. C.J. Campbell), pp. 351-356. Cambridge University Press, Cambridge, UK.

Santos-Filho, M., Bernardo, C.S.S., Van der LaAn Barbosa, H. W., Gusmão, A.C., Jerusalinsky, L. \& Canale, G.R. (2017) A new distribution range of Ateles chamek (Humboldt 1812) in an ecotone of three biomes in the Paraguay River Basin. Primates, 58, $441-448$.

Soares-Filho, B., Rajão, R., Macedo, M., Carneiro, A., Costa, W., Coe, M. et al. (2014) Cracking Brazil's Forest Code. Science, 344, 363-364.

Soares-Filho, B.S., Nepstad, D.C., Curran, L.M., Cerqueira, G. C., GARCiA, R.A., Ramos, C.A. et al. (2006) Modelling conservation in the Amazon basin. Nature, 440, 520-523.

Soberón, J. \& NakAmURA, M. (2009) Niches and distributional areas: concepts, methods, and assumptions. Proceedings of the National Academy of Sciences of the United States of America, 106, 19644-19650.

Terborgh, J. (1983) Five New World Primates: A Study in Comparative Ecology. Princeton University Press, Princeton, USA.

UNEP-WCMC (2016) World Database on Protected Areas User Manual 1.3. UNEP-WCMC, Cambridge, UK. Http://wcmc.io/ WDPA_Manual [accessed 30 July 2018].

van Schaik, C.P., Terborgh, J.W. \& Wright, S.J. (1993) The phenology of tropical forests: adaptive significance and consequences for primary consumers. Annual Review of Ecology and Systematics, 24, 353-377.

Villero, D., Pla, M., Camps, D., Ruiz-Olmo, J. \& Brotons, L. (2017) Integrating species distribution modelling into decision-making to inform conservation actions. Biodiversity and Conservation, 26, 251-271.

Wallace, R.B. (2008) Factors influencing spider monkey habitat use and ranging patterns. In Spider Monkeys: Behavior, Ecology and Evolution of the Genus Ateles (ed. C. Campbell), pp. 138-154. Cambridge University Press, Cambridge, UK.

Wallace, R.B., Mittermeier, R.A., Cornejo, F. \& Boubli, J.P. (2008) Ateles chamek. In The IUCN Red List of Threatened Species 2008. Http://dx.doi.org/10.2305/IUCN.UK.2008.RLTS.

T41547A10497375.en [accessed 30 July 2018]. 